\title{
A CONSTRUÇÃo HISTÓRICA DO AGRONEGÓCIO E A QUESTÃo AGRÁRIA
}

\section{LA CONSTRUCCIÓN HISTÓRICA DEL AGRONEGOCIO Y LA CUESTIÓN AGRARIA}

\author{
${ }^{1}$ Celso Lucas Fernandes Oliveira
}

\section{RESUMO}

O presente trabalho faz uma abordagem histórica, desde a "modernização conservadora" da agricultura até a atual realidade do agronegócio, buscando demonstrar como se deu o processo de "reprimarização" da economia brasileira. Portanto, este estudo tem como objetivo analisar a maneira pela qual a produção primário-exportadora se consolidou como modelo econômico e o papel do Estado nesse contexto, a partir das políticas públicas adotadas pelos diversos governos do período em análise. Além disso, o artigo visa verificar como a questão agrária foi tratada nos diferentes contextos políticos e econômicos do país e como o tema é abordado na atual conjectura do agronegócio no Brasil.

Palavras-chave: Modernização conservadora, Agronegócio, Agroexportações, Questão agrária

\section{RESUMEN}

El presente trabajo realiza una abordaje histórica, desde la "modernización conservadora" de la agricultura hasta la realidad actual del agronegocio para demostrar cómo ocurrió el proceso de "reprimarización" de la economía brasileña. Así, este estudio tiene como objetivo analizar la forma en que la producción y exportación primaria se consolidó como un modelo económico y el papel del Estado en este contexto, a partir de las políticas públicas adoptadas por los diferentes gobiernos de la época estudiada. Además, el artículo pretende ver cómo se trató la cuestión agraria en los diferentes contextos políticos y económicos del país, y como el tema es abordado en la actual situación del agronegocio en Brasil.

Palabras-claves: Modernización conservadora, Agronegocio, Agroexportaciones, Cuestión agraria

\footnotetext{
1 Mestrando em Direito Agrário pela Universidade Federal de Goiás - UFG, Goiás (Brasil). E-mail:
} celso_lucas@hotmail.com 


\section{INTRODUÇÃO}

Para que seja possível compreender a atual conjuntura do agronegócio no Brasil e as consequências que o modelo econômico baseado na agroexportação traz para o país hoje, é necessário analisarmos, historicamente, como se chegou até a realidade hoje enfrentada.

O presente estudo tem como ponto de partida a chamada modernização conservadora, período de desenvolvimento da agricultura brasileira que ocorreu durante o regime militar e teve como base uma política de modernização da setor agrícola, a partir de tecnologias provenientes da indústria, sem que fossem realizadas maiores modificações na estrutura fundiária.

Posteriormente, no segundo item do trabalho, será analisado o período de transição entre a modernização conservadora e a economia do agronegócio, demonstrando como agricultura foi tratada a partir da crise cambial do início da década de 1980 até o início dos anos 2000, passando pelos governos neoliberais da década de 1990.

Por fim, no terceiro item, o trabalho pretende demonstrar como o agronegócio se consolida atualmente no Brasil como modelo econômico, gerando o que alguns autores chamam de processo de "reprimarização" da economia. Ademais, serão abordadas as formas por meio das quais o capital internacional se insere hoje na meio agrário brasileiro, bem como discutidas as consequências de todo esse processo e a realidade da questão agrária.

Dessa forma, o presente estudo busca analisar o modo como se deram as políticas ligadas ao desenvolvimento da agricultura desde o período denominado de modernização conservadora até o agronegócio na atualidade, com o objetivo de se verificar como a questão agrária vem sendo tratada nos diversos contextos econômicos e políticos do país.

\section{MODERNIZAÇÃO CONSERVADORA DO AGRÁRIO NO BRASIL}

Apesar de o processo de modernização da agricultura no Brasil ter tido seus primeiros passos ainda na década de 1950, com a importação de meios de produção considerados mais modernos, foi a partir da década de 1960, em especial com o início dos governos militares em 1964, que surgiram planos de desenvolvimento econômico ${ }^{1}$ que tinham como objetivo, no que tange à produção agrícola, modernizar o campo, inserindo a agricultura na realidade da produção capitalista, com o objetivo de adequar a produção dos bens primários ao capital financeiro (DELGADO, 2012, p. 13-15). 
Dessa forma, durante esse período, o objetivo era transformar a agricultura baseada em técnicas tradicionais e métodos ainda rudimentares em uma agricultura mecanizada, com a utilização de equipamentos e insumos produzidos pela indústria. Essa modernização e reestruturação do campo se deu por meio da formação do chamado Complexo Agroindustrial no Brasil (CAI).

Segundo Müller (1989, p. 45):

O complexo agroindustrial, CAI, pode ser definido, em termos formais, como um conjunto formado pela sucessão de atividades vinculadas à produção e transformação de produtos agropecuários e florestais. Atividades tais como: a geração destes produtos, seu beneficiamento/transformação e a produção de bens de capital e de insumos industriais para as atividades agrícolas; ainda: a coleta, a armazenagem, o transporte, a distribuição dos produtos industriais e agrícolas; e ainda mais: o financiamento, a pesquisa e a tecnologia e a assistência técnica.

Portanto, o Complexo Agroindustrial era a concretização dessa ideia de modernização da agricultura brasileira, representava a estrutura e os mecanismos criados, com o incentivo estatal, para que a agricultura passasse a incorporar as tecnologias produzidas pela indústria para a produção agrícola.

A respeito da industrialização na agricultura e do surgimento do CAI, Müller (1989, p. 60) afirma que "a agricultura brasileira transitou do predomínio do modo tradicional de produzir para o predomínio do modo moderno, que combina insumos e serviços industriais com terra e trabalho".

A formação do chamado CAI se deu, portanto, da relação que surge entre a agricultura e a indústria, passando a existir entre tais atividades uma interdependência. Com a introdução de tecnologias no campo, os produtores buscavam aumentar a sua rentabilidade, uma vez que a mecanização, juntamente com os insumos, permite ampliar a área cultivável e garantir o incremento da produção.

\footnotetext{
${ }^{1}$ Ver o planos de governo para a agricultura em: GONÇALVES NETO, Wenceslau. Estado e agricultura no Brasil: política agrícola e modernização econômica brasileira (1960-1980). São Paulo: HUCITEC, 1997, p. 126-135.
} 
Além disso, a modernização do setor agrário foi considerada necessária devido ao contexto que o país vivia. Era crescente a industrialização e urbanização. Assim, utilizou-se como justificativa para a mecanização no campo a necessidade de se aumentar a produção de alimentos, bem como de matérias primas para a produção industrial, visando às exportações e o equilíbrio da balança comercial (MÜLLER, 1989, p. 28-44)

Dessa forma, argumentava-se que a agricultura era um entrave ao desenvolvimento econômico do país, não sendo capaz de responder às necessidades do setor urbano-industrial. No entanto, esse discurso foi, em grande parte, criado a partir da pressão de empresas multinacionais que investiram seu capital na indústria de equipamentos e insumos agrícolas e tinham como objetivo ampliar sua produção, a partir da introdução de suas tecnologias na agricultura brasileira (MÜLLER, 1989).

Além disso, o Estado teve grande importância no processo de modernização do campo, pois foi o responsável por garantir que a tecnologia, que era necessária para o incremento da produção rural, com o objetivo de garantir o desenvolvimento econômico nacional, fosse implementada. A transformação das técnicas de produção agrícola foi possível graças ao incentivo estatal, que ocorreu por meio do crédito rural, ou seja, o financiamento por parte do Estado visando permitir o acesso dos produtores aos equipamentos e insumos necessários (DELGADO, 2012, P. 13-15)

Entretanto, apesar de a justificativa para a modernização da agricultura estar centrada na necessidade de ampliar a produção alimentar, garantir o fornecimento de matérias-primas e aumentar o volume de exportações, esse modelo econômico foi fortalecido diante do interesse do capital internacional que estava investido na indústria nacional e necessitava expandir a produção de bens e insumos para a agricultura ou aumentar a produção e exportação, a partir da matéria-prima brasileira. Em ambos os casos o interesse capitalista foi fundamental na industrialização da agricultura no país e contou com os incentivos do Estado (PALMEIRA, 1989, p. 93-101).

Conforme ressalta Müller (1989, p. 34):

Com a integração indústria e agricultura no período de 1960-80, deparamo-nos com empresas e grupos econômicos que influenciam poderosamente a dinâmica das atividades agrárias, com profundas repercussões em suas estruturas. Mas na própria agricultura surgem empresas e grupos econômicos, que com suas congêneres industriais, fazem parte do poder econômico com interesses nas atividades agrárias. 
No entanto, deve-se considerar que o modelo de modernização da agricultura no Brasil trouxe consequências que vão além da ordem econômica, trazendo implicações sociais e políticas para diversos grupos.

Nesse sentido, afirma Müller (1989, p. 63):

[...] entende-se por modernização tecnoeconômica a alteração da composição orgânica do capital (técnica e/ou de valor) em função nas terras. Juntamente com a alteração na sociabilidade rural. Em outras palavras, a modernização é o resultado da interação entre a industrialização do campo, agroindustrialização das atividades agrárias e mudanças sociais e políticas entre os grupos sociais.

Assim, deve-se considerar a forma pela qual se deu a modernização do campo no Brasil, caracterizada pela falta de políticas que buscassem a reforma da estrutura fundiária e a melhoria das condições de vida do trabalhador do campo e dos pequenos produtores rurais. A concentração de terras foi mantida e os incentivos à produção para suprir às necessidades da indústria levou ao aumento da monocultura de exportação.

Segundo Palmeira (1989, p. 87):

Essa modernização, que se fez sem que a estrutura da propriedade rural fosse alterada, teve, no dizer dos economistas, "efeitos perversos": a propriedade tornou-se mais concentrada, as disparidades de renda aumentaram, o êxodo rural acentuou-se, aumentou a taxa de exploração da força de trabalho nas atividades agrícolas, cresceu a taxa de auto-exploração nas propriedades menores, piorou a qualidade de vida da população trabalhadora do campo. Por isso, os autores gostam de usar a expressão "modernização conservadora".

Portanto, o processo de modernização agrícola no Brasil é denominado por vários autores como modernização conservadora, uma vez que, apesar de trazer melhorias e modificações do ponto de vista de incremento da produção, a partir da inserção de tecnologias na agricultura, não permitiu uma reestruturação verdadeira no campo, principalmente com relação à reforma agrária e a melhoria nas condições de trabalho e na qualidade de vida do trabalhador, agravando a expropriação de terras e o êxodo rural. (PALMEIRA, 1989; DELGADO, 2012, p. 13-19).

Portanto, a modernização conservadora trouxe consequências negativas para aqueles que dependiam do trabalho agrícola. Diversas foram as modificações e os problemas agravados por esse processo, conforme afirma Gonçalves Neto (1997, p. 107):

É interessante notar que as transformações que ocorrem no agro, a partir da segunda metade dos anos 60, fortemente pressionada pela expansão do capital industrial, promovem uma reviravolta muito grande em toda a extensão da sociedade brasileira. Ao lado das violentas transferências de populações para o setor urbano, que é promovido por amplo conjunto de fatores, tais como mecanização, a substituição de culturas intensiva em mão-de-obra pela pecuária, o fechamento da fronteira, a aplicação da legislação trabalhista no campo, ou simplesmente pelo uso da violência, etc., ocorre também uma reformulação na mão-de-obra restante no interior das propriedades, com 
eliminação dos parceiros, agregados, etc., pela disseminação do trabalho assalariado, sobretudo nas grandes propriedades, que se modernizam e se transformam em empresas. Restou às pequenas propriedades a possibilidade da subordinação ao capital industrial, a marginalização, o esfacelamento ou a venda e migração para os centros urbanos.

A modernização conservadora, ocorrida durante os governos militares, se desenvolveu sem que fossem feitas alterações significativas na estrutura fundiária do país, caracterizada pela concentração das propriedades nas mãos de poucos e pela grande quantidade de terras improdutivas. A reforma agrária nunca foi colocada como integrante nesse processo de modernização (PALMEIRA, 1989).

Há de se ressaltar, ainda, que o papel do Estado foi fundamental para o desenvolvimento desse modelo de modernização que ocorreu no Brasil. Ao contrário do que pode se pensar, a modernização não ocorreu pela simples vontade e ação dos próprios empresário rurais, mas sobretudo por meio de políticas governamentais, tais como créditos subsidiados, incentivos fiscais, criação do Serviço Social Rural, programas de transferência de terras públicas para particulares e o Estatuto da Terra (PALMEIRA, 1989).

Nesse sentido, Palmeira (1989, p. 99) afirma que:

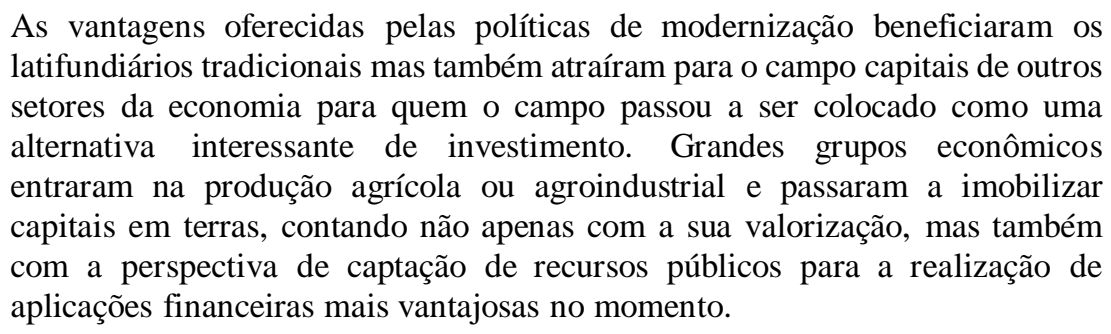

O modelo adotado pelo governo militar tinha como objetivo uma aceleração da industrialização, que foi considerada como um processo de modernização, sem a realização de reformas estruturais. A modernização verificada na agricultura nos anos de 1960 e 1970 não teve qualquer perspectiva de realização de uma efetiva reforma agrária, optando-se por um desenvolvimento capitalista no campo com a manutenção de uma estrutura fundiária anterior (NAKATANI; FALEIROS; VARGAS, 2012).

Portanto, os "efeitos perversos" da modernização conservadora do campo são consequências da própria forma de ação adotada pelo Estado, o qual priorizou o interesse do empresariado e dos grandes grupos econômicos, em detrimento de políticas públicas que resultassem efetivamente na melhoria dos problemas sociais enfrentados pelo trabalhadores rurais e pequeno produtores, deixando de lado qualquer perspectiva de reforma agrária e contribuindo para o fortalecimento das desigualdades sociais. 


\section{O PERÍODO DE TRANSIÇÃO: DA MODERNIZAÇÃO CONSERVADORA AO AGRONEGÓCIO CONTEMPORÂNEO.}

\subsection{A crise cambial na década de $\mathbf{1 9 8 0}$}

A agricultura brasileira, entre os anos de 1965 e 1981, viveu um período de grande crescimento, sem uma efetiva modificação da estrutura agrária. No entanto, no início da década de 1980, a economia brasileira se encontra diante de uma difícil crise, gerada em grande parte pelo endividamento externo, resultando em um período de estagnação econômica.

Nesse contexto, Nakatani, Faleiros e Vargas (2012, p. 228) afirmam que "nos anos 1980, em função do esgotamento do modelo brasileiro e da correlata crise da dívida, impõe-se a necessidade premente de geração de saldos comerciais crescentes, gerados, evidentemente, pela grande agricultura".

No mesmo sentido, Delgado (2012, p. 78) diz que:

A maneira como o establishment econômico promoverá a gestão da crise da
dependência externa, a partir da reversão do ciclo econômico de crescimento
em 1982, requer uma participação expressiva do setor agrícola e das cadeias
agroindustriais conexas na exportação de mercadorias. Esta passa a ser essencial
na geração de saldos de comércio exterior, que por sua vez suprem as
necessidade de financiamento do déficit em conta corrente do balanço de
pagamentos.

Portanto, diante do quadro de recessão vivido pelo Brasil nos primeiros anos da década 1980, a agricultura passou a ter um papel fundamental, tendo sido a grande responsável pela solução da crise a partir da expansão das agroexportações que foram capazes de restabelecer a balança comercial e frear o aumento da dívida externa.

Percebe-se, assim, que o modelo de crescimento econômico implementado durante as duas décadas anteriores pelos governos militares já não se sustentava. Com a mudança na forma de atuação do Estado no âmbito econômico, visando solucionar a crise que atingiu o pais a partir de 1982, a agricultura passou a ocupar um novo espaço, diante do contexto que se vivia.

Se antes, dentro da lógica do modelo de modernização conservadora, a agricultura era vista como um setor atrasado, o qual não era valorizado, devendo se modernizar nos moldes da indústria e servir de suporte à produção industrial, agora passa a ser um setor estratégico, desempenhando um função essencial para possibilitar a equação do déficit da balança comercial brasileira. Como se verá mais adiante, o entendimento e a forma de utilização que se tinha nesse período é a que se vê, atualmente, 
de maneira mais intensificada, com a economia do agronegócio e a o chamado processo de "reprimarização".

Assim, diante da crise instalada, entre 1982 e 1983, o governo militar, por meio de ações coordenadas por Delfim Neto, então Ministro do Planejamento, buscou aumentar o saldo da balança comercial brasileira, a partir, basicamente, da expansão de produtos primários e agroprocessados, provenientes da nova fronteira agrícola que se estabelecia da Região Centro-Oeste (DELGADO, 2012, p. 79-81).

De acordo com os dados do Instituto de Pesquisa Econômica Aplicada (IPEA), a área colhida de cana-de-açúcar aumentou de 2.768.514 de hectares em 1980, para 4.272.602 de hectares em 1990. Já a produção de soja teve sua área ampliada de 8.774.023 hectares para 11.487.303 hectares, entre 1980 e 1990². Verifica-se, portanto, que no fim do período dos governos militares e durante toda a década de 1980, houve um grande incremento da produção agrícola, sobretudo da monocultura de exportação.

Nessa perspectiva, um exemplo claro das políticas de incentivo à produção agrícola, com o objetivo de reverter a situação de recessão que o país vivia após o chamado período do "milagre econômico", foi o projeto Proálcool, o qual tinha como objetivo ampliar a produção do biocombustível produzido a partir da cana-de-açúcar, buscando reduzir a utilização dos combustíveis derivados de petróleo e, consequentemente, das importações desse produto (NAKATANI; FALEIROS; VARGAS, 2012, p. 228).

Apesar de ter tido uma fase inicial entre os anos de 1975 e 1979, foi a partir de 1980, diante da explosão nos preços do barril de petróleo e da grande dependência das importações para suprir as necessidades internas, que o governou passou a adotar medidas para a efetiva implementação do programa. Dessa forma, a

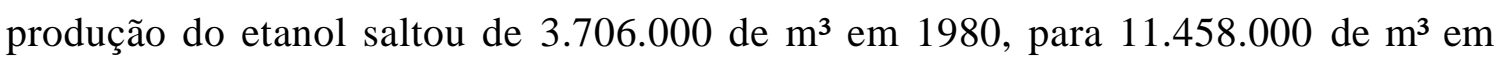
$1987^{3}$.

\footnotetext{
${ }^{2}$ Fonte: IPEA. Disponível em: <http//www.ipeadata.gov.br>. Acesso em: 04 ago. 2014.

${ }^{3}$ Fonte: ÚNICA. Disponível em: 〈http://www.unicadata.com.br〉. Acesso em: 10 set. 2014.
} 


\subsection{AS MUDANÇAS NOS GOVERNOS NEOLIBERAIS DA DÉCADA DE 1990}

Nos últimos anos da década de 1980, com o fim do regime militar e no contexto da redemocratização política, a realidade econômica já era fortemente influenciada pelos ideais do neoliberalismo. Embora tal tendência política e econômica não tenha se refletido no texto da Constituição de 1988, que trouxe garantias de ordem social, a partir de diretrizes para o fortalecimento de políticas públicas, os governos posteriores à promulgação da nova Constituição tiveram claramente um caráter neoliberal, com práticas que visavam acabar com a ação Estado em determinadas áreas, como a economia (DELGADO, 2012, p. 83).

Os governos do período pós-constituinte, nos anos de 1990, diante da influência neoliberal, fizeram diversas modificações na estrutura administrativa do Estado, que acabaram com instituições estatais criadas no contexto da modernização conservadora, bem como com as políticas públicas voltadas para o incremento da produção e expansão da agricultura criadas no contexto de crise que o país viveu na década anterior.

Com relação à agricultura, as modificações trazidas pelo governos de Fernando Collor, Itamar Franco e Fernando Henrique Cardoso buscaram a minimização na intervenção do Estado, acabando com instituições estatais ligadas à atividade agrícola, como os institutos de fomento por produto, bem como diminuindo o volume de crédito rural concedido, ou seja, houve uma redução substancial nas atividades estatais de estímulo à agricultura (DELGADO, 2012, p. 83).

A partir de 1994, com a adoção do Plano de Estabilização Monetária (Plano Real), houve uma crescente abertura para a entrada de capital externo, deixando de lado políticas que buscassem garantir saldos comerciais positivos. Nas palavras de Delgado (2012, p. 81):

[...] os novos ventos da liquidez internacional conduzem a política de comércio exterior a uma forte liberalidade, ancorada no tripé câmbio sobrevalorizado, tarifas ultramitigadas e desregulamentação no campo de políticas de fomento agrícola e industrial.

No entanto, a falta de regulação da entrada de capital externo causou o desequilíbrio da balança comercial, resultando em um grande déficit. Essa liberalização, aliada à falta de estímulos do Estado por meio de políticas de incentivo à produção e comércio agrícola, gerou a queda dos preços das commodities. Dessa forma, entre 1994 e 1999, houve um desestímulo claro às exportações e uma grande elevação das importações 
(DELGADO, 2012, p. 83-87).

Diante desse contexto, em que ficou evidente o recuo na expansão da agricultura, houve uma drástica queda no valor da renda dos produtores agrícolas, bem como desvalorização do preço das terras.

Verifica-se, portanto, que, após a adoção do Plano Real, deixou-se de lado a política de incentivo à produção agrícola nacional e de exportações de commodities, que foi implementada durante a década de 1980 visando solucionar a crise cambial. Entretanto, os constantes déficits enfrentados durante o governo FHC, devido à política econômica adotada, geram outra crise de liquidez internacional que atinge a economia brasileira.

Diante disso, em 1999, o governo se vê obrigado a recorrer aos empréstimos internacionais do Fundo Monetário Internacional (FMI), para compensar o prejuízo da balança comercial e solucionar a crise cambial. Além disso, a política de comércio exterior é alterada, buscando garantir saldos positivos. Nesse contexto, a agricultura apresenta-se como o setor estratégico para reverter o déficit enfrentado pelo comércio externo brasileiro (DELGADO, 2012, p. 87-88).

A política agrícola, portanto, volta a ser uma prioridade, tendo em vista o potencial da agricultura brasileira na produção de commodities destinadas à exportação e, consequentemente, como solução para enfrentar a crise cambial vivida. Neste sentido, conforme afirma Delgado (2012, p. 93):

\footnotetext{
Outra vez, como ocorrera na primeira crise da dívida em 1982, os setores primário-exportadores são escalados para gerar esse saldo comercial. Nesse contexto, a agricultura capitalista, autodenominada de agronegócio, volta às prioridades da agenda política macroeconômica externa e da política agrícola interna. Isto ocorre depois de forte desmontagem dos instrumentos de fomento agrícola no período procedente (anos 1990) [...]
}

Assim, a política de comércio exterior do governo brasileiro, após um período de total liberalização e falta de incentivos à produção interna e exportação, que predominou durante a década de 1990, é alterada com objetivo de melhorar o saldo da balança comercial brasileira, sendo as exportações de produtos agrícolas o principal alvo dos incentivos governamentais, já que tal atividade passou a ser vista como a solução para a crise.

Dessa forma, como veremos no item a seguir, nos anos 2000 houve uma retomada de investimento do capital financeiro na agricultura, com expressivo ganho de produtividade no setor agrícola, diante do fenômeno chamado de "reprimarização" do política comercial brasileira (DELGADO, 2012; NAKATANI; FALEIROS; VARGAS, 2012) 
Entretanto, há que se ressaltar a maneira como a questão agrária foi tratada durante todo esse período, desde o início da década de 1980 até início dos anos 2000, marcado por duas crises cambiais vividas no Brasil, inclusive no período "entre crises", em que houve uma total desvalorização da renda agrícola e do preço das terras, devido à liberalização comercial, como já se apresentou.

Verifica-se que, mais uma vez, não houve a real implementação de medidas por parte dos governos que visassem a modificação da estrutura fundiária no país. A concentração da propriedade das terras se manteve, diante da falta de políticas de reforma agrária efetivas.

Mesmo durante os governos neoliberais da década de 1990, que, por meio de políticas econômicas altamente liberalizantes, geraram a desvalorização no preço da terra e o nível da renda dos produtores, o que facilitaria, do ponto de vista financeiro, a reforma agrária, pois a tornaria mais barata, bem com diminuiria o poder econômico dos latifúndios, não houve qualquer atuação estatal nesse sentido. Não se utilizou de mecanismos que pudesse reorganizar a estrutura fundiária, em favor da pequenas e médias propriedades (DELGADO, 2012, p. 82).

\section{A ECONOMIA DO AGRONEGÓCIO NA ATUALIDADE}

A partir do ano 2000, até os dias atuais, o agronegócio se consolida como um modelo de acumulação de capital no campo, sendo direcionado pelas políticas públicas do próprio Estado. Portanto, a retomada do investimento do capital financeiro na agricultura, a partir de políticas estatais, marca esse novo período (DELGADO, 2012, p. 89-97). Nesse contexto, durante a primeira década dos anos 2000 , houve uma expansão da produção agrícola e das exportações de produtos primários, ao contrário da situação que se observou na década de 1990, conforme já exposto. Assim, verifica-se um grande aumento na produção de commodities e nos preços dos produtos.

Conforme ressalta Delgado (2013, p. 63):

\footnotetext{
Em pouco mais de uma década, 1999-2012 o pais quintuplica em dólares suas exportações - passando de 50,0 bilhões a 250,00 bilhões. Nesse "boom" exportador, os produtos primários - "básicos" e "semi-elaborados", ganham posição protagônica, enquanto as manufaturas vão saindo das "exportações" e ingressando paulatinamente nas "importações" - (entre os anos 1995/99 e $2008 / 10$ os produtos 'primários' pulam de $44,0 \%$ para $54.3 \%$ da pauta exportadora, enquanto os 'manufaturados decrescem proporcionalmente).
}

A expansão econômica das commodities conduz ao que alguns autores chamam de "reprimarização" da economia brasileira, dada a ampliação da demanda externa por 
alimentos e matérias-primas para a indústria em geral (DELGADO, 2013; NAKATANI; FALEIROS; VARGAS, 2012). Tal fenômeno resulta em uma especialização primárioexportadora, que passa a ser vista como o modelo de crescimento econômico a ser adotado pelo Brasil.

A economia do agronegócio vai além da estratégia econômica de acumulação de capital no setor primário. O próprio setor agrícola deixa de ser visto somente como subsidiário à industrialização, ao contrário do que ocorreu no período da chamada modernização conservadora. Na visão de Delgado (2013, p. 67):

\begin{abstract}
Diferentemente de "Modernização Conservadora" dos militares, suportada pelo crescimento industrial e pelas Armas da República, a economia do agronegócio se estruturou ao abrigo da inserção primário exportadora de uma economia mundial em ciclo de forte expansão do comercio internacional de "commodities". Mas forjou-se internamente como bloco hegemônico, manipulando com grande competência a arma ideológica do consenso político.
\end{abstract}

Dessa forma, o preço das mercadorias agrícolas, bem como as demais condições que favorecem o incremento da renda agrícola, influenciam diretamente no valor das terras. Portanto, diante do contexto de crescimento da produção primária brasileira e do aumento do volume de exportação de commodities, observa-se uma valorização do preço das propriedades rurais e também dos valores dos arrendamentos (DELGADO, 2012, p. 97-99).

Diante desse contexto, marcado pela valorização das terras, bem como pelo aumento significativo das monoculturas de exportação, observa-se o avanço da concentração de terras no país. Entre os anos de 2003 e 2010, segundo dados do Instituto Nacional de Colonização e Reforma Agrária - INCRA, a área das grandes propriedades aumentou de 214.843.865 para 318.904.739 hectares, o que representa um crescimento de $48,4 \%$ desse tipo de propriedade no período, totalizando $55,8 \%$ de todos os perfis de propriedades.

Por outro lado, os minifúndios aumentaram de 38,9 milhões para 46,6 milhões de hectares, as pequenas propriedades de 74,1 milhões para 88,7 milhões de hectares, e as médias propriedades de 88,1 milhões para 113,8 milhões de hectares. Entretanto, de maneira geral, a quantidade de propriedades desses três tipos diminuiu (NAKATANI; FALEIROS; VARGAS, 2012, p. 19-20).

Outro ponto que se deve levar em consideração é a aquisição de terras por empresas transnacionais com o objetivo de produzir mercadorias de alta demanda no mercado externo, tais como soja, cana-de-açúcar, milho, dentre outros. Além disso, no contexto atual do agronegócio, o crescente aumento no valor das terras atrai o interesse 
dos investidores que aplicam seu capital no meio rural, dada a atual valorização fundiária no Brasil. Portanto, existem empresas estrangeiras que buscam investir na aquisição de propriedades rurais, diante da possibilidade de ganhos expressivos na sua posterior venda.

Sobre o atual contexto do agronegócio no Brasil, Carvalho (2013, p. 32):

O agronegócio assim reproduzido tem obtido resultados financeiros que lhe são altamente favoráveis apesar da escolha pela oferta e comercialização de produtos para exportação em detrimento dos produtos de consumo alimentar e da absoluta indiferença com a dominação exercida pelas empresas capitalistas transnacionais no agrário brasileiro. (...)

Essa concentração de renda e da riqueza pelas empresas capitalistas no campo vem se concretizando - como outrora no período colonial, com o apoio massivo das políticas públicas governamentais.

Além disso, o autor acrescenta:

A apropriação privada da natureza, amplo senso, e a desnacionalização das agroindústrias com predomínio de capital da burguesia nacional, tem permitido que sob novas roupagens e discursos se racionalize a apropriação das terras para mantê-las como reserva de valor, já que mundialmente vai se tornando relativamente exígua a disponibilidade de terras agricultáveis ainda não apropriadas pelos capitalistas e, portanto, que ainda não se inseriram no mercado mundial de terras. (CARVALHO, 2013, p. 34)

Portanto, o autor defende a ideia de que está ocorrendo uma desnacionalização do meio agrário, uma vez que o país depende cada vez mais de uma economia globalizada, tendo em vista a sua economia estar baseada substancialmente na produção agroexportadora. Assim, a agricultura, bem como o próprio meio rural encontra-se submetido aos interesses do capital internacional e, especificamente, de algumas empresas transnacionais que se instalam no Brasil para produzir commodities a preços mais baratos e também aquelas interessadas no próprio mercado de terras.

Nesse contexto, as empresas que operam o agronegócio, com o objetivo ampliar a sua acumulação de capital, utilizam estratégias diversas, como a concentração de terra, a produção agropecuária e florestal em larga escala, o monocultivo, o uso intensivo de agrotóxicos, hormônios, transgênicos, além do desrespeito às características socioculturais dos povos do campo e expropriação de camponeses (CARVALHO, 2013, p. 31). Tudo isso traz consequências negativas de ordem econômica, ambiental e social.

A conjuntura atual no agronegócio no Brasil tem contribuído para que a questão agrária ganhe novos contornos e, sobretudo, continue sem solução. Esse quadro de reafirmação do modelo primário-exportador em larga escala, influenciado diretamente pela ação do capital internacional, tem colaborado, inclusive com a participação do governo, a partir de políticas públicas, para a manutenção da estrutura fundiária marcada 
pela concentração da propriedade da terra, bem como para a falta de melhoria das condições de vida no meio rural.

Portanto, o agronegócio contemporâneo e a forma de ação adotada pelos governos nos últimos anos torna cada vez mais difícil a realização efetiva de uma reforma agrária, contribuindo, por outro lado, para que a estrutura de propriedade da terra no Brasil, que pouco se modificou nos últimos 50 anos, se perpetue.

\section{CONCLUSÃO}

Diante do que foi apresentado, pode-se concluir que, desde o período denominado de modernização conservadora até o agronegócio contemporâneo, o modelo de produção agroexportadora é aquele que tem predominado no Brasil, como ocorreu historicamente.

Além disso, foi possível perceber a importância do Estado enquanto fomentador da produção agrícola e como as políticas públicas são fundamentais para direcionar o rumo dos investimentos na agricultura e a possibilidade de tais investimentos trazerem resultados positivos para a economia. Isso pode ser verificado nas diferentes formas com que os governos trataram essa atividade nas três últimas décadas, sendo que, durante os governos neoliberais da década de 1990, percebe-se claramente que a falta de estímulos do Estado para a produção agrícola gerou um queda dos preços dos produtos e, consequentemente, da renda dos produtores e do preço das terras.

Há que se ressaltar também o papel fundamental do Estado que pode ser percebido de forma semelhante tanto na modernização conservadora quanto na atual conjuntura do agronegócio, uma vez que a forma de atuação estatal foi decisiva para garantir que a agricultura atingisse uma grande produção e contribuísse para a sustentação da economia.

No entanto, a diferença que se verifica, ao continuar traçando um comparativo entre a modernização conservadora e o agronegócio na atualidade, é justamente a visão da agricultura e o papel que ela passa a ocupar. Enquanto, naquele momento histórico, a busca por uma modernização da agricultura se pautava nas necessidades da indústria, uma vez que o setor agrícola era visto como atrasado, na atualidade, o agronegócio, em si mesmo, é visto como a atividade capaz de sustentar o crescimento econômico do Brasil e a ampliação do país no mercado internacional. 
Quanto à questão agrária, o que se conclui é que a estrutura fundiária pouco se alterou dentro do período histórico analisado. Seja nos governos ditatoriais ou nos governos democráticos pós regime militar, a concentração da propriedade da terra se manteve e pouco foi feito, por meio de políticas públicas, visando mudar esse cenário e garantir uma modificação da realidade no campo e diminuição da desigualdade enfrentada pelos que vivem no meio rural e dele dependem.

Portanto, diante do que foi exposto, o economia atual do agronegócio contribui para reafirmar os problemas enfrentados no meio rural, sendo que uma modificação estrutural no setor agrário requer uma reorganização do próprio modelo econômico primário-exportador adotado pelo Brasil, a partir de políticas públicas que efetivamente busquem enfrentar os desafios econômicos, sociais e ambientais que surgem nesse cenário.

\section{REFERÊNCIAS BIBLIOGRÁFICAS}

ABRAMOVAY, Ricardo. Paradigmas do capitalismo agrário em questão. 2 ed. Campinas: Editora da UNICAMP, 1998. AMIN, Samir; VERGOPOULOS, Kostas. A questão agrária e o capitalismo. 2 ed. Rio de Janeiro: Paz e terra, 1977.

CARVALHO, Horácio Martins de. A expansão do capitalismo no campo e a desnacionalização do agrário no Brasil. Revista da Associação Brasileira de Reforma Agrária (ABRA), edição especial, p. 61-68, jun. 2013.

DELGADO, Guilherme Costa. Do capital financeiro na agricultura à economia do agronegócio: mudanças cíclicas em meio século (1965-2012). Porto Alegre: Editora da UFRGS, 2012.

Economia do agronegócio (anos 2000) como pacto do poder com os donos da terra. Revista da Associação Brasileira de Reforma Agrária (ABRA), edição especial, p. 61-68, jun. 2013.

. A questão agrária no Brasil, 1950-2003. In: JACCOUD, Luciana. Questão social e políticas sociais no Brasil contemporâneo. Brasília: Ipea, 2005. p. 51-90.

GONÇALVES NETO, Wenceslau. Estado e agricultura no Brasil: política agrícola e modernização econômica brasileira (1960-1980). São Paulo: HUCITEC, 1997.

MARES, Carlos F. A função social da terra. Porto Alegre, Sergio Antônio Fabris Ed., 2003. 
MENDONÇA, Sônia Regina de. A nova hegemonia do patronato agrário brasileiro: da Organização das Cooperativas Brasileiras à Associação Brasileira de Agrobusiness. Revista Antítese, Goiânia, n. 2, p. 11-29, 2006.

. A classe dominante agrária: natureza e comportamento - 1964-1990. In: STÉDILE, João Pedro (Org.). A questão agrária no Brasil. São Paulo: Expressão Popular, 2006. v. 5.

MÜLLER, Geraldo. Complexo agroindustrial e modernização agrária. São Paulo: HUCITEC, 1989.

NAKATANI, Paulo; FALEIROS, Rogerio Naques; VARGAS, Neide Cesar. Histórico e os limites da reforma agrária na contemporaneidade brasileira. Serv. Soc. Soc., São Paulo, n. 110, p. 213-240, abr./jun. 2012.

PALMEIRA, Moacir. Modernização, Estado e questão agrária. Estudos Avançados, São Paulo, v. 3, n. 7, p. 87-108, set./dez. 1989. Disponível em: http://www.scielo.br/pdf/ea/v3n7/v3n7a06.pdf. Acesso em: 18 ago. 2014.

TEIXEIRA, Gerson. A sustentação política e econômica do agronegócio no Brasil. Revista da Associação Brasileira de Reforma Agrária (ABRA), edição especial, p. 61-68, jun. 2013.

STÉDILE, João Pedro (Org.). A questão agrária no Brasil: o debate tradicional 15001960. São Paulo: Expressão Popular, 2005. 